\title{
Effects of Parental Involvement in Academic Wellness of Primary School Learners in the Lubombo Region, Eswatini
}

\author{
Thabsile. W. Mabuza Racheal Mafumbate* \\ University of Eswatini, Department of Educational Foundations and Management, Faculty of Education
}

\begin{abstract}
This study sought to determine the effects of parental involvement on the academic performance of primary school learners in rural schools in the Lubombo region of Eswatini. The study employed a mixed method approach and the concurrent triangulation design was used. The study was guided by the ecological systems theory by Bronfenbrunner and wellness theory by Hettler. The findings revealed that education was a shared responsibility between the parents/ guardians and the school and most of the parents and guardians showed very little interest in their children's learning. The majority of the learners did not stay with their biological parents and it affected their performance at school. The study recommended that the school should engage all parents and prompt them on the importance of parental involvement by creating plenty of opportunities for parents to be actively engaged through parent/school meetings, prize giving days, homework among other things. Moreover, it was recommended that parents and communities should be helped to better appreciate the value and benefits of education to their children.
\end{abstract}

Keywords: social factors, academic achievement, disadvantaged children, rural schools

DOI: $10.7176 / \mathrm{JCSD} / 51-05$

Publication date:September $30^{\text {th }} 2019$

\section{Introduction}

A person's education is closely linked to his or her life experiences, income, and well-being (Battle \& Lewis, 2002). Education is a tool of development and is the most important weapon to bring changes in the society by removing superstitions and make people wise and rational. Education is the prime equipment to make the people of a state or country skilled and civilized, and leads the development of a nation through individual development of its citizen (Islam \& Khan, 2017). Education has been highlighted as one of the main Sustainable Developmental Goals (SDGs) that African countries including Eswatini need to achieve, as it has been pointed out as an instrument for eradicating poverty and as a tool for economic development (World Bank, 2002). Family background is key to a student's life and outside of school. Moreover, it is the most important influence on student learning and includes factors such as socio-economic status, two-parent versus single parent households, divorce, parenting practices and aspirations, maternal characteristics and family size (Majoribanks, 1996). The environment at home is a primary socialization agent and influences a child's interest in school and aspirations for the future (Tailor, 2005).

\section{Statement of the problem}

In 2007, Shiselweni region schools were the worst performing in the country followed by Lubombo region schools. Lubombo schools experienced the highest repetition rates (World Health Organization, 2015). Examination Council of Eswatini, (2016) reported that Lubombo region schools failed to shine academically. Concerning poverty the data indicated that rural areas were significantly more disadvantaged compared to urban areas (World Health Organization, 2015). One of the major Sustainable Developmental Goals (SDGs) is to eradicate poverty (United Nation, 1992). Education and Training Sector Policy (2011) posits that there should be equal access for quality education to all. The government of Swaziland has introduced Free Primary Education (FPE) and the orphan and vulnerable children (OVC) grant as a way of combating poverty. Furthermore, it has supplied free textbooks, exercise books, stationeries and food to all primary schools. Added to that, qualified teachers are being employed by the government through its wing which is the Ministry of Education and Training. Despite all these efforts, leaners in the Lubombo region are still not performing well. This situation is very worrying considering the financial and material investment made by the government to provide quality education to all primary school learners in the kingdom of Eswatini. The study, therefore, had addressed the problem by finding out the effects of parental involvement on academic wellness of learners in the Lubombo region rural primary schools.

\section{Review of related literature}

Hargreaves (2002) reported that in Germany students with parents who are involved in their school tend to have fewer problems, and better academic performance and are more likely to complete high school than students whose parents are not involved in their school. Mushtag and Khan (2012) in Pakistan noted that social factors like attendance in the class, teacher-student ratio, presence of trained teachers in schools, distance of school, 
communication, learning facilities, proper guidance and family stress are contributing factors to poor academic performance in students. Hussain (2006) established that students face a lot of problems in developing positive study habits and further argued that the guidance from parents and teachers indirectly affect the performance of students.

In a similar study, Thomas (2015) in Chicago concluded that social class, home condition, peer relations, aspiration levels and academic inclination are social factors that affect academic performance. Salameh (2012) in Dubai revealed that parental care and encouragement towards children and their education as well as the provision of facilities, such as adequate stimulating reading materials, enhance their willingness to learn and develop their skills. In similar vein, Pnantoan (2008) establishes that students with two parents operating in supportive roles are $52 \%$ more likely to enjoy school than students whose parents are disengaged with what is going on at school.

Slaten (2006) stated that the way a child is reared affects his or her overall growth; specifically, the psychological development and academic performance. Borak, Kawser, Haque and Sharmin (2016) concur with Slaten (2006) in their study where they found out that students having high authoritative parenting styles showed high academic results than those who are authoritarian, permissive and uninvolved parenting styles. Furthermore, Kang and Moore (2011) ascertain that unlike authoritarian parents, punishment is very rarely used in permissive homes and children are commonly given greater opportunity to make their own decisions in life. The uninvolved style is predominantly characterised by low levels of both warmth and control. This often reflects the parents' emotional detachment from the children as they are often seen responding only to their children's needs (Hong, 2012).

On the other hand, Ploeg (2002) states that students from disrupted families are less likely to complete fouryear college than their peers from intact biological families. He further stated that intact biological families save earlier and more (and expect to spend more to support) their children's first year in college. Johnson (2005) asserts that children from divorced families often fail and are at risk emotionally. In contrary, he further stated that this may not be completely applicable in all instances of broken homes as some children irrespective of home background or structures may work hard and become successful in life. Lee and Madyun (2009) state that individuals growing up in disadvantaged neighbourhoods are more susceptible to pervasive, self-replicating underdevelopment than their peers growing up in socially and economic stable neighbourhoods as a direct consequence of larger social factors far beyond the influence of individuals.

Adepoju and Akinyele (2013) conducted a study in Nigeria and found out that family disintegration affects the success rate of a child at school both academically and behaviourally. Ifeyinwa (2017) states that a child whose mother left the house because of frequent fighting and quarrelling with the father will never be happy in school and will not concentrate in his studies, his mind will easily go back to the occurrence at home. Diemer and Ali (2009) posit that children from higher social class backgrounds tend to be more successful in developing career aspirations and are generally better prepared for the world of work because of access to resources such as career offices, guidance and counsellors, better schools and higher level "social actors". Landsberg, Kruger and Swart (2011) concluded that it is necessary for parents and teachers to create safe and secure surroundings where children can experience warmth, acceptance and provide most of their needs for them to fulfil their learning task.

Mwirichia (2013) in Kenya found out that students whose parents are involved in checking homework showed higher achievement than students whose parents are not involved in checking homework. Furthermore, Mwirichia (2013) stated that many parents are tremendously involved, often volunteering to help in their children's classroom activities, communicating well with their child's teacher, assisting with homework, and understanding their child's individual academic strengths and weaknesses, whereas some are not directly involved with their child's education.

A study conducted by Emmanuel (2015) in Tanzania revealed that most students especially girls are engaged in activities such as helping in household chores, caring for their siblings when their parents are away and taking care of the sick children in their family thus limit them to have enough time for study and make revision concerning their study which affect their academic performance. Borak, Kawser, Haque and Sharmin (2016) in their study which investigated the association of parental acceptance-rejection on academic achievement found out that parental acceptance significantly improved academic achievement whereas, parental rejection lessened the academic achievement of students. Kapinga (2014) in Tanzania ascertains that majority of parents were not involved in the learning of their children as well as in the school improvement programmes.

Coming closer home, Mutodi (2014) in South Africa noted that there is a significant positive relationship between parental involvement and students' performance. The findings suggested that parents' involvement through home works, creating conducive home environments for studying and motivating and setting realistic expectations enhance performance. Conversely, Bayat, Louw and Rena (2014) in the Western Cape Province of South Africa revealed that factors that are collectively playing a major role in the poor performance of learners were the lack of parental involvement and parents were not interested in their children both in their general wellbeing and in their school work. 


\section{Theoretical framework}

An integrative theoretical framework was adopted in the study. It was underpinned by the ecological systems theory by Bronfenbrunner (1979) and the wellness theory by Hettler (1984). According to the ecological system theory the child's development is influenced by five systems which are the micro-system, meso-system, exosystem, macro-system and chrono-system. This theory looks at a child's development within the context of the system of relationships that form his or her environment. Bronfenbrenner's theory defines complex "layers" of environment, each influencing a child development. The interaction between factors in the child's maturing biology, his immediate family or community environment, and the societal landscape fuels and steers his development. Changes or conflict in any one layer will ripple throughout other layers (Ofusu-Asiamah, 2013). The heart of Bronfenbrenner's ecological systems theory is that the school, home and community affect a student's academic achievement. For this reason, all three components (parents, school, and community) should work harmoniously to achieve the student's good academic performance.

On the other hand, the wellness theory determines six factors which contribute to an individual psychological wellbeing, contentment and happiness known as the six dimensions of wellness. These six dimensions of wellness are occupational, emotional, spiritual, intellectual, physical and social. These theories fit well with the study because the needs of a child are offered within the systems in which the child interacts with, direct or indirect. So, if these systems are not encouraging and nurturing the child, his or her development will be affected, thus affecting his or her performance at school. Again, if the mental health of the learner is stable it will enable him or her to be focussed and concentrate in class.

\section{Research Methodology}

This study employed a mixed method research approach using concurrent triangulation design. The researcher collected survey and interview data at the same time and then the results were compared. Therefore, in using both the qualitative and quantitative data in the study provided a more comprehensive understanding required to inform decision making. The targeted population of the study were head teachers, classroom teachers and students in the 113 Lubombo region primary schools. Teachers were involved in the study because they are the ones who monitor the students' academic progress and learners were involved because they were rich informants. The learners were in grade 5 and grade 7 aged from 10 years to 16 years in the Lubombo region of Eswatini. The sample size were 10 rural schools in the Lubombo region which comprised of 10 head teachers, 60 learners and 40 teachers. Therefore, the total number of respondents was 110 . Purposive sampling was used to sample the 10 schools, as they were sampled based on the researcher's judgement that they were easily accessible. Teachers and learners were randomly selected from the staff list and class list respectively so that every member had an equal chance to be selected in the study. Homogeneous purposive sampling was used to sample sixteen learners from two schools. The researchers analysed the average marks of the learners for term 1 and term 2 from the record books to obtain their performance. Thematic analysis, inferential and descriptive statistics were used to analyse the data. Credibility, dependability, transferability and confirmability were considered in this study.

\section{Findings from focus group discussions}

The participants revealed that for them to excel in their school work, they need proper guidance and adequate support from their parents. They responded that parents should help them with their homework and even check what they have been learning at school. The following are themes that emerged from the data: 1) parental guidance and support, 2) Effective parenting style and 3) Family stability.

\section{Theme 1: Parental guidance and support}

From the study it was reported that education begins at home and that there had to be a shared responsibility between the parents/guardians and the school. The participants revealed that in order for them to reach academic achievement parents must be involved and participate in the educational process. It also emerged that the more parental involvement the more they are likely to excel in their academics. They suggested that their parents/ guardians should help them when studying or when writing their home works and also supervise them. One participate alluded that:

I live with my both parents and my father is working in one of the government offices. My mother is a teacher by profession and she supervises me when I am doing my school work and also help me to study that is why I am excelling in my school work. My mother also communicate my academic performance with the teacher (Participant \# 7, 12 years old, grade 7 male student, FGDs).

Another participant stressed that:

When I am given work to take home there is no one who help me with my homework as both of my parents are working in the sugar cane farms and come back home so tired and they do not supervise me. When my parents tell me to study, I go to my bedroom and pretend as if I am studying and then I will sleep without reading any of my books. They will not even come 
to my bedroom to check if I am really studying or not (Participant \# 2, 11 years old, grade 5

female student, FGDs, school A).

\section{Theme 2: Effective parenting style}

The findings of the study revealed that parenting styles are necessary to fulfil the developmental needs of children and eventually improve their quality of life. It was found that authoritative parenting style was the most parenting style in enhancing the academic performance of students where the parents set some limits for their children at the same time they were responsive to their children's emotional needs. Ten out of sixteen participants $(63 \%)$ when asked if there were clear rules at home that were set by their parents/ guardians, most of their responses was "No". One of the participants reported that:

At home I live with my grandmother, my mother is working around Manzini and my father died when I was doing grade 3 . There are no rules that are set by my grandmother as a result when I come home from school I just go to play with my friends and come back late or even sleep over my friend's place, no one will bother asking me where I was. There are no study rules at home I only read my books when I feel like (Participant \# 6, 11 years old, grade 5 male student, FGDs, school A).

In support of the above statement another participant said:

My uncle help me with my homework since I lost both of my parents. There was no time where I have failed to do my homework because my uncle supervise and help me with my work. There are clear rules in my family, for example at $5 \mathrm{pm}$ to $6 \mathrm{pm}$ it is study time and at $9 \mathrm{pm}$ we all go to sleep and we do not watch television on school days we only watch it during weekends or when schools are closed (Participant \# 3, 14 years old, grade 7 male student, FGDs, School A).

\section{Theme 3: Family stability}

On this issue, generally, this study found out that most of the participants were not staying with their parents. Only four participants out of sixteen said that they lived with both parents, some said they live with only one parent, others are living with guardians and one came from a child headed family. Some of the reasons that emerged from the participants of not staying with their parents were divorce, separation and death of their parents. Twelve out of sixteen $(75 \%)$ of the participants do not live with both of their parents because of the reasons stated above. The study also revealed that family is the most important influence in a child's life and parents act as first teachers. One of the participant had this to say:

Some children depend on their parents and family to protect them and provide their needs and this is not the case with me because my parents died and left me with three siblings to take care of as I am the eldest child in the family. It is very difficult for me because of the multiple roles I have to play to my siblings such as providing their needs and taking care of them. Although we are being helped by the community motivator in some of our needs, but it makes me not to have a full concentration on my studies and I am affected psychologically (Participant \# 1, 15 years old, grade 7 female student, FGDs school A).

\section{Findings from questionnaires}

Parents' lack of interest in their children's work: Most head teachers $(70 \%$; $=10)$ feel that parents lack interest in their children's work. Only $10 \%$ of respondents said they are not sure if parents really lack interest in their work. Those respondents who disagree are $10 \%$ and those who strongly disagree are also $10 \%$ of the population. Summary of the findings is presented in Figure 1 


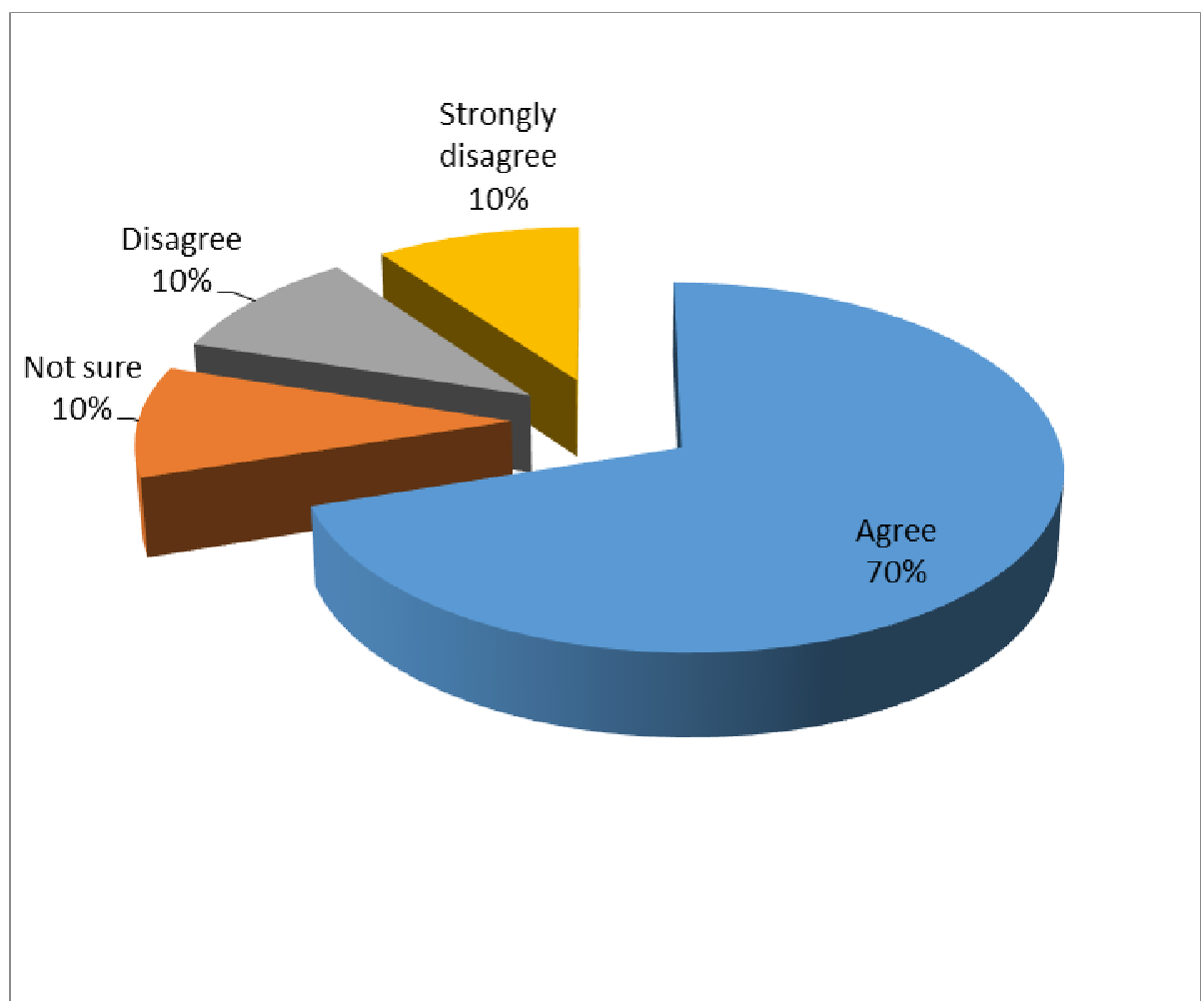

Parents assisting children with school work: The assistance that parents give to their children on school work contributes to better academic performance. A small proportion $(31 \%, \mathrm{n}=40)$ of the primary school teachers who participated in the study agree or strongly agree with the opinion that parents assist their children with school work at home. Majority $(69 \%, n=40)$ of the respondents did not agree with the opinion that children receive assistance from their parents on their schoolwork. Of those who did not agree, $10 \%$ strongly disagree, $37 \%$ disagree and $22 \%$ are not sure. Table 1 summarises the findings.

Table 1: Parents assist children with schoolwork

\begin{tabular}{lcc}
\hline Response & Percent & Cumulative Percent \\
\hline Strongly agree & 3 & 3 \\
Agree & 28 & 31 \\
Not sure & 22 & 53 \\
Disagree & 37 & 90 \\
Strongly disagree & 10 & 100 \\
Total & 100 & \\
\hline
\end{tabular}

Family breakdown: Family breakdown such as through single parent families or orphaning may cause poor performance in students. The teachers who participated in the study were positive about this assertion. $32 \%$ strongly agree, $50 \%$ agree whilst $5 \%$ were not sure and 13\% disagreed. Figure 2 summarises the findings. 


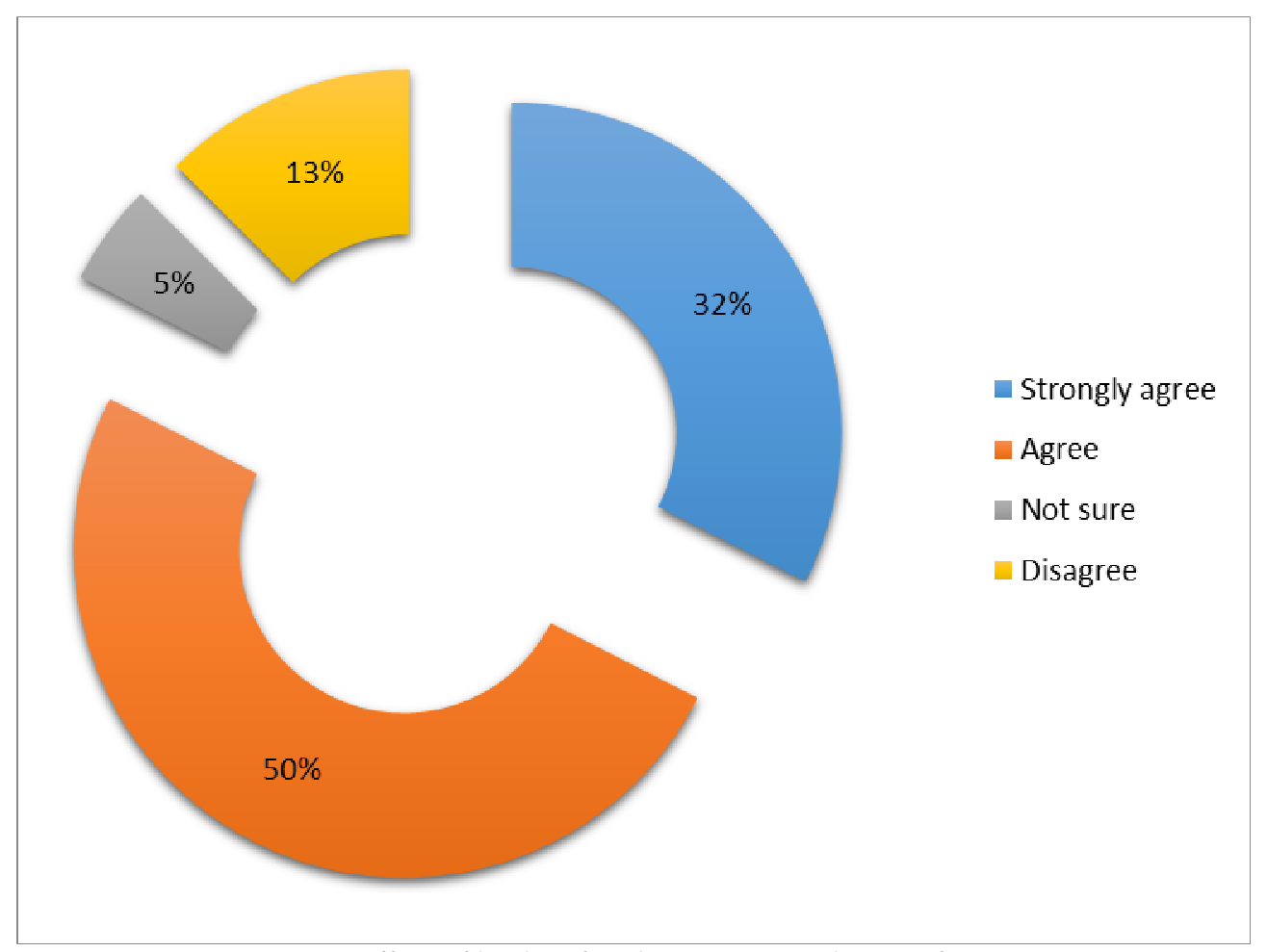

Figure 2: Effect of broken family units on student performance

Regular person(s) stayed with: The research explored the impact of the person(s) whom learners regularly stay with on their academic performance. The study showed that $32 \%$ of leaners stay with both their parents, $31 \%$ mostly stay with their mothers, $27 \%$ with guardian and $10 \%$ with a relative. Analysis of the findings shows that most of the students who stay with both their biological parents perform better in school than those who stay with non-parent guardians. Of the 22 learners who said they perform excellently, 10 stay with parents, 7 with their mother, 3 with a guardian and 2 with a relative. The results show no significant relationship between above average and below average performance and the person staying with the learner.

\section{Discussions on qualitative findings}

The study revealed that education was a shared responsibility between the parents/guardians and the school. The study revealed that for learners to reach academic achievement parents must be involved and participate in the educational process. Mwirichia (2013) in Kenya found that students whose parents are involved in checking homework showed higher achievement than learners whose parents are not involved in checking homework. It also emerged that the more parental involvement the more they are likely to excel in their academics, such findings are very consistent with Mutodi (2014) who noted that there is a significant positive relationship between parental involvement and students' performance.

The study revealed that the authoritative parenting style is the most parenting style in enhancing the academic performance of learners where the parents set some limits for their children at the same time they are responsive to their children's emotional needs. The findings of the study may be viewed as complementary to Dehyadegary (2012) who revealed that authoritative style of parenting had a positive and significant influence on academic achievement among adolescents which means that adolescents who had parent with authoritative style were more successful in school.

The findings of the study revealed that majority of the learners did not stay with their biological parents. Some of the reasons that emerged from the participants of not staying with their parents were divorce, separation and death of their parents. The study also revealed that family is the most important influence in a child's life and parents act as first teachers. The findings of the study can be aligned to the views of Akinyele (2013) who states that family integration permanently weakens the relationship between children and parents, and children from such homes are less likely to progress to tertiary education and hold rewarding jobs. In contrary, Johnson (2005) stated that some children irrespective of home background or structures may work hard and become successful in life.

\section{Discussion on Quantitative Findings}

The findings of this study indicated that most of the participants do not stay with their parents. Only twenty five percent $(25 \% ; n=16)$ of the learners involved in the study were staying with both parents, some said they live 
with only one parent, others are living with guardians while others are from child headed families. In this regard it was the findings of the study that family is the most important influence in a child's life and parents act as first teachers, this was provided in the questionnaires administered to the participants. Such findings are relatively consistent with the findings of Landsberg, Kruger and Swart (2011) who concluded that it is necessary for parents and teachers to create safe and secure surroundings where children can experience warmth, acceptance and provide most of their needs for them to fulfil their learning task. Additionally, it was the findings of the study as drawn from most head teachers $(60 \% ; n=10)$ that family incoherence is one of the factors that affect students' performance at school. Furthermore, all the head teachers involved $(100 \% ; n=10)$ were positive that family breakdown has got an impact on learners' performance. The findings of the study are comparative to the findings made by Thomas (2015) in Chicago who concluded that social class, home condition, peer relations, aspiration levels and academic inclination are social factors that affect academic performance.

Most of the teachers involved in the study $(70 \% ; n=10)$ feel that parents lack interest in their children's work. Additionally, a sizeable chunk of the teachers $(48 \% ; n=40)$ also confirmed that parents take very little interest in their learners' school work and this was detrimental to the academic success of the learners. The findings of the study are in line with the findings of Bayat, Louw and Rena (2014) study in the Western Cape Province of South Africa who found out that factors that are collectively playing a major role in the poor performance of learners were the lack of parental involvement and parents were not interested in their children both in their general wellbeing and in their school work.

\section{Conclusion}

Based on the findings above it was concluded that:

- family is the most important influence in a child's life and parents act as first teachers;

- $\quad$ parents lack interest in their children's work, therefore, they were found to be non-cooperative; and

- $\quad$ students coming from disintegrated families were reported to be struggling in class.

\section{Recommendations}

1. The Ministry of Education and Training (MoET) may consider introducing more basic education programmes aimed at educating mature people. Parents may be encouraged to enrol for such programmes to improve their level of competence and proficiency in helping learners with key aspects of the school programme such as homework.

2. The School may engage all parents and prompt them on the importance of parental involvement. The study gave evidence to the effect that most learners indicated that their parents were disengaged from their academic work. The schools should create plenty of opportunities for parents to be actively engaged through parent/school meetings, prize giving days, homework among other things.

3. Parents Teacher Association (PTA) may be activated in all schools to have more communication between the school and parents by organizing circular meetings to keep parents updated about their children's performance.

\section{References}

Battle, J., \& Micheal, L. (2003). The Increasing Significance of Class: The Relative Effects of Race and Socioeconomic Status on Academic Achievement. Journal of Poverty. 6(2), 21-35.

Bronfenbrenner, U. (1979). The Ecology of Human Development. Cambridge, MA: Harvard University Press.

Considine, G., \& Zappala, G. (2002). The Influence of Social and Economic Disadvantage In the Academic Performance of School Students in Australia. Journal of Sociology, 38(2), 129- 148.

Deslandes, R. \& Brtrand, R. (2005). Motivation of Parent Involvement in Secondary-Level Schooling. The Journal of Educational Research, 98(3), 164-175.

Frorentino, S., \& Marjorie,L. (2013). The Effect of Social Factors in the Academic Performance of the Bbte Students. Thesis. University of the Philippines College of Education.

Gall, M. D., Gall, J. P., \& Borg, W. R. (2007). Educational Research: An Introduction (8 ${ }^{\text {th }}$ ed.). New York: Pearson Education.

Ifeyinwa, M. C. (2017). Effect of Socio-economic Status of Parents on Academic Performance of Students in Technical Colleges in Delta State of Nigeria. International Journal of Research, 5(2), 185-196.

Islam, M. R., \& Khan, Z. N. (2017). Impact of Socio-economic status on academic Achievement among the Senior Secondary School students. An International Journal of Education and Applied Social Science, 8(3), $1-5$.

Johnson, R. B. \& Onwuegbuzie, A. J. (2004). Mixed Methods Research: a research paradigm whose time has come. Educational Research, 33(7), 14-26.

Kapinga, O. S. (2014). The Impact of Parental Socio-economic Status on Students' Academic Achievement in 
Secondary Schools in Tanzania. International Journal of Education, 6(4), 25-38.

Kim, E. (2002). The Relationship between Parental Involvement and Children's Educational Achievement in the Korean Immigrant Family. Journal of Comparative Family Studies, 33(4), 515-529.

Lee, M., \& Madyuni, N. (2009). The Impact of the Neighbourhood Disadvantage on the Black- white Achievement gap. Journal of Education for Students Placed at Risk, 14(2), 148-169.

Lee, J. S. \& Bowen, N. K. (2006). Parent Involvement, Cultural Capital, and the Achievement Gap among Elementary School Children. American Research Journal, 43(2), 193-218

Maric, M. \& Sakac, M. (2014). Individual and Social Factors Related to Students' Academic Achievement and Motivation for Learning. Suvremena Psychology, 17(1), 63-79.

Ministry of Education Policy. (2011). The Swaziland Education and Training Sector Policy. Mbabane. Swaziland.

Michubu, M. J. (2013). Socio-economic Factors Influencing Students'Academic Performance in Public Secondary Schools in Igembe South District, Kenya. Thesis. University of Nairobia. Kenya.

Mugenda, O. M., \& Mugenda, A. G. (2008). Research Methods. Nairobi: Acts Press.

Muthoni, K. L. (2013). Relationship between Family Background and Academic Performance of Secondary Schools Students: A Case of Siakago Division Mbeere North District. Kenya. Thesis. Nairobi.

Mutodi, P. (2014). The Impact of Parental Involvement on Student Performance: A case Study of a South African Secondary school. Mediterranean Journal of Social Sciences 5(8), 279- 289.

Mwaura, J. M. (2010). Strategies Employed by Secondary School Principals to Improve Academic Performance in Embu West District. Thesis. Kenyatta University. Kenya.

Salameh, W. (2012). The Impact of Social and Economic Factors on Students' English Language Performance in EFL Classrooms in Dubai Public Secondary Schools. Thesis. The British University.

Shenton, A.K. (2004). Strategies for Ensuring Trustworthiness in Qualitative Research Projects. Education for Information, 22(3), 63-75.

Thomas, R.F. (2015). Social Factors Affecting Academic Performance: Further Evidence, the Schooling Review. University of Chicago Press Journal, 65(4), 415-422.

United Nation, (2007). Sustainable Development in Action. United Nation. 